\title{
$\left({ }_{2}\right)$ \\ Pakistan Social Sciences Review www.pssr.org.pk
}

\section{RESEARCH PAPER}

\section{Material Evaluation of English Textbook of BS Criminology: An ESP Analysis}

\author{
Dr. Hira Ali1 Samrina Sana² Asma Shaheen Afzal ${ }^{3}$
}

1. Lecturer, Department of English, University of Sargodha, Sargodha, Punjab, Pakistan

2. Visiting Lecturer, Department of English, University of Sargodha, Sargodha, Punjab, Pakistan

3. Visiting Lecturer, Department of English, University of Sargodha, Sargodha, Punjab, Pakistan

PAPER INFO

Received:

March 21, 2021

Accepted:

July 05, 2021

Online:

July 25, 2021

\section{Keywords:}

ESP (English for Specific Purpose),

Material

Evaluation,

Textbook BS

Criminology

*Corresponding

Author

tahirajebeen08@gma

il.com

\section{ABSTRACT}

The present research aims to investigate the pedagogical value and suitability of the English textbook of BS Criminology at the University of Sargodha, Main Campus. The study adheres to the material evaluation in ESP. The data comprises 14 sample analyses. For evaluating the textbook Miekley's checklist has opted. In this study, the total participants were fifty who were undertaking the course of ESP. All the participants were taken from 19 to 21 years. The sampling was done from the University of Sargodha, Department of Criminology. According to the results, the English taught to the students is accurate and fulfilling their communicative needs. The ESP textbook has key features which are proved to be motivational for the students. It is implied for further researches in ESP to evaluate the materials according to the needs of the learners. Moreover, it recommends the modification and redesigning of the courses according to the needs and wants of the learners.

\section{Introduction}

In the ESP (English for Specific Purposes) material evaluation is a substantial skill. It can be described as is mainly to determine the effect of the material that has been prepared on the ones who will be using it (Tomlinson, 2003). It involves analysis of textbooks and finding out contents that would meet the learner's needs. In material evaluation, the suitability of contents according to the needs is investigated. Material evaluation tells about the appropriateness of the course being taught in the class and its feasibility for students in achieving their objectives and goals. The verdict of prevailing material provides a base for the development of more materials. The material evaluation must be a structured process. In terms of systematic and organized evaluation, McDonough and Shaw, (2003), proposed a model for material evaluation. The model suggests a dichotomous evaluation of the material. 


\section{External Evaluation}

It involves investigation of external content such as cover, color scheme, Title page, preface, introduction and table of contents. It mainly focuses on attraction through title page, persuasive blurb, quality of print and book review. We can marginalize the external evaluation up to the layout of the book.

\section{Internal Evaluation}

It is an extensive evaluation of material. It involves assessment of material inside the book, content text of the book and its suitability with the components that are evaluated in the external evaluation like material must be in accordance with the title of the book. Moreover, it involves content matched with student's needs and answer keys for activities given in the book and some impressive teacher notes regarding topics discussed in the chapters.

While answering the question: how materials should be evaluated? Hutchinson and Waters (1987) proposed four steps procedure of material evaluation.

\section{Four steps for Material Evaluation}

\section{Defining Criteria}

Defining criteria deals with the standard on the basis of which evaluation of material would be accomplished and how much that criteria would be significant in the process of evaluation.

\section{Objective Analysis}

The objective analysis deals with the question of what extent material meets with the demands of criteria and answers the question that for whom the material is intended for and what are the aims of the material.

\section{Subjective Analysis}

The subjective analysis deals with the demands of the criteria being used in the assessment of materials i.e. what qualities material should have to meet with the defined standard it answers the question that who are the learners and what are the aims of the course.

\section{Matching}

Matching deals with realization of needs of learners and answers the question that to what extent material copes with the needs of learners.

The present research is divided into the following sections i.e. Part one includes the introduction. Part two discusses the literature review. Part three 
includes the term Evaluation in detail and its three types named as preliminary, performance and revised evaluation. Part four discusses the methodology including participants, a framework of the study, instruments, research questions and procedure. Part five confers the analysis and representation of the data. Part six discusses the recommendations and implications of the study. Finally, part seven discusses the conclusions of the study.

\section{Literature Review}

Azaarnoosh and Ganji (2014) investigate the material evaluation of textbooks of management. Research is qualitative research and is conducted in Iran. For evaluation, they have used the Miekley checklist. In this study, the researcher covers different aspects such as the role of these textbooks in ESP, role in developing English skills in the workplace. So, their main focus is on vocabulary, grammar, attractiveness, and the physical make-up of the text. The study follows that textbooks are appropriate but should be modified to meet the exact need of students.

Another recent research is done by_El-Sakran (2012). He discusses the material evaluation of textbooks of Islamic study and Arabic. El-Sakran analyses internal as well as external evaluation of ESP. Besides the material and learning activities, he argues that while evaluating the textbooks, cover, or title page, its color scheme and design should be under consideration. He concludes his findings that this book contains specific Islamic and Arabic cultural heritage so that it can be used as a textbook for ESP.

Baleghizadeh (2011) analyzes the procedures that are used while evaluating the textbooks for ESP students. His work aims to appraise the general appropriateness of the book. It is a quantitative study and a questioner based on twenty items is used as a data tool for thirty participants from Sociology Department. The study has six aspects of findings, are the layout of materials and have practical concerns with materials in relation to the course objectives, linguistic issues, skills and strategies, activities and variety of tasks and subject matter, they have deduced from the study that the book taken under study is not appealing for students because the caliber of the students is not kept in view while designing the book. The book is not motivating and has problems with language and vocabulary.

In "Material Evaluation" a writer argues that while evaluating material, there must be criteria such as the attractive layout of the book, and the course content must be according to the needs and level of the students along with the book review and teacher notes. Besides these factors, there is another factor that it must meet the learners' needs and priorities.

Abbasian and Mahdavi (2012) state the role of ESP in humanities and engineering. The researchers have checked the suitability in accordance with ESP for Humanities and Engineering. It is a quantitative study in which there are 180 students of ESP and 30 teachers from both disciplines have participated in the study and data is collected through two questioners while statistical analysis is done to 
analyze the data and to go for findings. The study concludes that the views of students are not compatible with the views of the teacher as former are satisfied while the later are not.

Al- Fraidan (2012) reveals findings of an evaluation of two ESP books of Business discipline. The researcher used the techniques of Hollett and Anderton. The study is conducted by using the methodology of McDonough and Shaw (2003) which involves concepts of internal and external evaluation and deduced a result that to meet the needs of students material of both books should be merged. None of these two books is self-sufficient to student's needs.

Maryam and Sara (2014) explore ESP books for students of Computer engineering, they evaluate this case study with the help of questioner based on 8 checklist references. Evaluation is made according to six paradigms which are named skills and strategies, aims and approaches, designing and organizations, practical consideration, topics, illustrations, language contents exercises. Data is analyzed through descriptive statistical analysis and it is found that despite the importance of these books on the academic level books are not so good as far as six paradigms are concerned.

\section{Evaluation}

Evaluation of the materials plays a significant role in making the academic performances of the students as well as of teachers better. It leads to the fulfillment of the needs of the learners and as a result, the syllabuses are modified and redesigned.

The evaluation may be of three types:

\section{Preliminary Evaluation}

Preliminary Evaluation is conducted before the commencement of the classes of ESP may be at for the sake of designing and developing a course. It is effective for better output of the prevailing course.

\section{Performance Evaluation}

Performance Evaluation is conducted after the completion of the course and the purpose of this evaluation is to judge the effectiveness of the course. Such kind of evaluation is significant to bring improvement in the prevailing course.

\section{Revised Evaluation}

Revised Evaluation is done during the teaching of the course. It is for modification in the course and to overcome its drawbacks. Revised evaluation is 
useful in the gradual development of the course and in competing with the needs of students.

According to Hutchinson and Waters (1987), there are some objectives of material. It should be motivated, it must be student-friendly, it should be the embodiment of learning tasks and provide a model for learning and using the language. If an ESP expert is clear with the objectives of the material, then he can play a significant role in material evaluation.

\section{Material and Methods}

The data comprises 14 sample analyses. The samples are designed according to the parameters of material evaluation of the textbook of ESP of Criminology. The study has been designed to explore the effectiveness of the textbook ESP that whether the textbook fulfills the wants of the students or not. For evaluating the textbook Miekley's checklist has opted. It consists of 14 questions that are responsible to inquire into the textbook with every possible aspect.

\section{Participants}

In this research work, Criminology Department was the main focus to choose the participants. In this study, the total number of participants was fifty. Out of fifty participants, fifteen were males and thirty-five were females undertaking the course of ESP. All the participants were taken from the younger group whose age showed a discrepancy from 19 to 21 years. The sampling was done from the University of Sargodha, Department of Criminology.

\section{Framework}

Our material for evaluation was the English coursebook and academic writings for the Criminology students. The students were supposed to fill the checklist provided by the researcher to make us accessible with the authenticity of the textbook that whether it is fulfilling the communicative needs of the learners or not. To conduct this work evaluates the checklist from Miekley's (2005) model was used each question was based on outcomes about language learning strategies useful for efficient learning. The suitability and appropriateness of the text were to be examined for the learners, teachers and for the whole program in which the learners strive to use the materials according to the contextual references.

The obtained data was analyzed with the help of SPSS. The evaluated results were shown with the help of tables showing the percentages and frequencies for the answers. The responses showed that the English language teaching to the students of criminology is effective and making them efficient enough to communicate in English language. The checklist included five main parts on the basis of which text book was analyzed. The five parts are content, syntax and lexis, worksheets and activities, the layout of the text and physical makeup, and as a final point context. 


\section{Instruments}

All the parts are related to the practical concerns to modify the syllabus according to learner's needs and wants.

\section{Course Objectives}

The objectives should be limited and measurable. They must be designed in such a way as they can be observable by placing the students according to their abilities. This can also pave the way to judge their skills as well to mark the students that how much capable they are and what are their fields of interest.

\section{Subject Matter}

The related subject matter should increase the learner's communicative competence and language proficiency. This may enhance their cognitive abilities concerning bilingualism. The subject matter is responsible to enhance their competence in L2.

\section{Linguistic Issues}

There should be various practices done by the learners because acquiring a language and increasing its competence leads to acquiring many ethical concerns related to the target culture.

\section{Skills}

The course should be designed intensively and must be incorporated with all the dimensions which are responsible to enhance the learner's academic writing, reading, listening and speaking.

\section{Nature of the Tasks and Material}

The tasks must not be exclusively based on the grammatical patterns only rather they must be incorporated with the other dimensions. Such interactive activities based on L2 and real-world tasks should be incorporated so that the students may gain experience of the target culture instead of just learning it theoretically from the books. The layout of the materials should be attractive and appealing to satisfy their aesthetic sense and provides them with an urge to study them further.

\section{Procedure}

Firstly, the participants were told about the research project and it was made clear that their data would purely be for research purposes and would not be misused. The provided data would not influence their grades. Finally, the opinions of the participants were required so that the usefulness of the textbook could be 
evaluated. Five scales were provided to them to answer: excellent, good, adequate, poor and lacking.

\section{Research Questions}

1- Whether or not the English taught to the students of criminology fulfills their needs?

2- Whether or not the vocabulary and grammatical rules presented in the book are helpful to enhance language proficiency and communicative needs?

3- Do the exercises and activities in accordance with the needs of the learners?

\section{Results and Discussion}

\section{Research Item: Content}

In response to the question: 'Is the subject matter presented either topically or functionally in a logical and organized manner? (Miekley, 2005). The following table addresses the results:

Table 1

'Is the subject matter presented either topically or functionally in a logical and organized manner?

\begin{tabular}{ccccc}
\hline & Frequency & Percent & Valid Percent & Cumulative Percent \\
\hline Excellent & 28 & 56.0 & 56.0 & 56.0 \\
\hline Good & 17 & 34.0 & 34.0 & 90.0 \\
\hline Adequate & 4 & 8.0 & 8.0 & 98.0 \\
\hline Poor & 1 & 2.0 & 2.0 & 100.0 \\
\hline Total & 50 & 100.0 & 100.0 & \\
\hline
\end{tabular}

As shown in Table 1 that 56 percent of students have shown their responses for scale 1, for which the highest frequency is 28 , which is excellent. The second highest frequency for this question is on scale 2, i.e. 17, which is good.

This shows that the subject matter presented in the book is organized manner. Content is essentially an important part of any text. The value of content is based on its authenticity and logicality. It must fulfill the required goals and demands of the reader. One of the basic requirements of content is that it should be properly organized in a proper logical manner and the responses have shown that the content is clear and adequate.

In response to the question: 'Are the reading selections authentic pieces of language'?(Miekley, 2005). Following table shows the results of the responses received during this research: 
Table 2

Are the reading selections authentic pieces of language'?

\begin{tabular}{ccccc}
\hline & Frequency & Percent & Valid Percent & Cumulative Percent \\
\hline Excellent & 15 & 30.0 & 30.0 & 30.0 \\
\hline Good & 22 & 44.0 & 44.0 & 74.0 \\
\hline Adequate & 11 & 22.0 & 22.0 & 96.0 \\
\hline Poor & 2 & 4.0 & 4.0 & 100.0 \\
\hline Total & 50 & 100.0 & 100.0 & \\
\hline
\end{tabular}

As shown in Table 2 that 44 percent of students have shown their responses for scale 2, for which the highest frequency is 22 , which is good. The second highest frequency for this question is of scale 1, i.e. 15, which is excellent. This shows the satisfaction of the students regarding the authenticity of the book. The piece of work being taught in the class should be from an authentic source. The highest frequency for Good scale is evident that their textbook includes the works from authentic sources. It promotes their language skills and critical thinking as well.

\section{Research Item: Vocabulary and Grammar}

In response to the question: 'Are the grammar rules presented logically and increasing order of difficulty? (Miekley, 2005). The following table shows the results for this question:

Table 3

Are the grammar rules presented logically and increasing order of difficulty?

\begin{tabular}{ccccc}
\hline & Frequency & Percent & Valid Percent & Cumulative Percent \\
\hline Excellent & 19 & 38.0 & 38.0 & 38.0 \\
\hline Good & 15 & 30.0 & 30.0 & 68.0 \\
\hline Adequate & 9 & 18.0 & 18.0 & 86.0 \\
\hline Poor & 4 & 8.0 & 8.0 & 94.0 \\
\hline Lacking & 3 & 6.0 & 6.0 & 100.0 \\
\hline Total & 50 & 100.0 & 100.0 & \\
\hline
\end{tabular}

As shown in Table 3 that 38 percent of students have shown their responses for scale 1, for which the highest frequency is 19, which is excellent. The second highest frequency for this question is on scale 2, i.e. 15, which is good. This shows that the textbook contains grammar rules and these are very much present with reasoning and in its complex forms. Vocabulary and grammar, considered pillars of language. Grammar rules should be presented in a good manner and there should be proper coherence and cohesion. The grammatical rules should be presented in order of increasing the level of difficulty. The responses have shown that the textbook functionally contains the grammar. In response to the question: 'Are the new vocabulary words presented in a variety of ways? (Miekley, 2005). The following table addresses the results for this question: 
Table 4

'Are the new vocabulary words presented in a variety of ways?

\begin{tabular}{ccccc}
\hline & Frequency & Percent & Valid Percent & Cumulative Percent \\
\hline Excellent & 19 & 38.0 & 38.0 & 38.0 \\
\hline Good & 21 & 42.0 & 42.0 & 80.0 \\
\hline Adequate & 6 & 12.0 & 12.0 & 92.0 \\
\hline Poor & 3 & 6.0 & 6.0 & 98.0 \\
\hline Lacking & 1 & 2.0 & 2.0 & 100.0 \\
\hline Total & 50 & 100.0 & 100.0 & \\
\hline
\end{tabular}

As shown in Table 4 that 42 percent of students have shown their responses for scale 2, for which the highest frequency is 21 , which is good. The second highest frequency for this question is for scale 1, i.e. 19, which is excellent. This shows that the vocabulary is presented in a variety of ways in the textbook. In addition to grammar, vocabulary is also important. Vocabulary beautifies the language. The use of synonyms and introducing new words and references grabs the attention of the students. There should be a proper emphasis on the vocabulary portion also. The responses have shown that the textbook does have loads of good vocabulary and functioning grammar. In response to the question: 'Are the new vocabulary words repeated in subsequent lessons to reinforce their meaning and use'?(Miekley, 2005). The result is as follows:

Table 5

Are the new vocabulary words repeated in subsequent lessons to reinforce their meaning and use'?

\begin{tabular}{ccccc}
\hline & Frequency & Percent & Valid Percent & Cumulative Percent \\
\hline Excellent & 13 & 26.0 & 26.0 & 26.0 \\
\hline Good & 19 & 38.0 & 38.0 & 64.0 \\
\hline Adequate & 13 & 26.0 & 26.0 & 90.0 \\
\hline Poor & 4 & 8.0 & 8.0 & 98.0 \\
\hline Lacking & 1 & 2.0 & 2.0 & 100.0 \\
\hline Total & 50 & 100.0 & 100.0 & \\
\hline
\end{tabular}

As shown in Table 5 that 38 percent of students have shown their responses for scale 2, for which the highest frequency is 19, which is good. The second highest frequency for this question is for scales 1 and 3, i.e. 13 for both, which is excellent and adequate respectively. This shows that the repetition of vocabulary emphasizes the meanings as they are used. Reinforcement plays a significant role in learning the concepts being laid in the texts. The responses have shown that the vocabulary words are repeated and meanings are reinforced in the textbook.

\section{Research Item: Exercises and Activities}

In response to the question: 'Are there interactive and task based activities that require students to use new vocabulary to communicate'?(Miekley, 2005). The result is as follows: 
Table 6

Are there interactive and task based activities that require students to use new vocabulary to communicate'?

\begin{tabular}{ccccc}
\hline & Frequency & Percent & Valid Percent & Cumulative Percent \\
\hline Excellent & 13 & 26.0 & 26.0 & 26.0 \\
\hline Good & 16 & 32.0 & 32.0 & 58.0 \\
\hline Adequate & 8 & 16.0 & 16.0 & 74.0 \\
\hline Poor & 9 & 18.0 & 18.0 & 92.0 \\
\hline Lacking & 4 & 8.0 & 8.0 & 100.0 \\
\hline Total & 50 & 100.0 & 100.0 &
\end{tabular}

As shown in Table 6 that 32 percent of students have shown their responses for scale 2, for which the highest frequency is 16 , which is good. The second highest frequency for this question is for scale 1, i.e. 13, which is excellent. This shows that the activities promote interaction and task based that require the students to use new vocabulary items. Exercises and activities are used for the evaluation of the learner. These are used to enhance communication skills. It might be in different forms, for example, fill in the blanks, multiple choice questions, open ended and close ended questions, true false, choosing alternatives, etc. such type of activities appears to be interesting and are usually attempted by learners for their evaluation. The responses have shown that the book is designed by interactive and task based activities for the students.

In response to the question: 'Do instructions in the textbooks tell students to read for comprehension? (Miekley, 2005). The result is as follows:

Table 7

'Do instructions in the textbooks tell students to read for comprehension?

\begin{tabular}{ccccc}
\hline & Frequency & Percent & Valid Percent & Cumulative Percent \\
\hline Excellent & 19 & 38.0 & 38.0 & 38.0 \\
\hline Good & 15 & 30.0 & 30.0 & 68.0 \\
\hline Adequate & 11 & 22.0 & 22.0 & 90.0 \\
\hline Poor & 4 & 8.0 & 8.0 & 98.0 \\
\hline Lacking & 1 & 2.0 & 2.0 & 100.0 \\
\hline Total & 50 & 100.0 & 100.0 & \\
\hline
\end{tabular}

As shown in Table 7 that 38 percent of students have shown their responses for scale 1 , for which the highest frequency is 19 , which is excellent. The second highest frequency for this question is for scale 2, i.e. 15, which is good. This shows that the instructions in the textbook demand that the students read it for comprehension. The communicative competence and ability to comprehend the texts of the students are enhanced by these kinds of activities. In response to the question: 'Do the exercises promote critical thinking of the text'?(Miekley, 2005). The result is as follows: 
Table 8

Do the exercises promote critical thinking of the text'?

\begin{tabular}{ccccc}
\hline & Frequency & Percent & Valid Percent & Cumulative Percent \\
\hline Excellent & 9 & 18.0 & 18.0 & 18.0 \\
\hline Good & 27 & 54.0 & 54.0 & 72.0 \\
\hline Adequate & 11 & 22.0 & 22.0 & 94.0 \\
\hline Poor & 2 & 4.0 & 4.0 & 98.0 \\
\hline Lacking & 1 & 2.0 & 2.0 & 100.0 \\
\hline Total & 50 & 100.0 & 100.0 &
\end{tabular}

As shown in Table 8 that 54 percent of students have shown their responses for scale 2, for which the highest frequency is 27 , which is good. The second highest frequency for this question is on the scale of 3, i.e. 11, which is adequate. This shows that the exercises promote critical thinking of the text. But the results have also shown that 22 percent of students have found it adequate which leads to a suggestion that the exercises should be improved and revised to make the learning of the students better. In response to the question: 'Do the activities facilitate student's use of grammar rules by creating situations in which these rules are needed'?(Miekley, 2005). The result is as follows:

Table 9

Do the activities facilitate student's use of grammar rules by creating situations in which these rules are needed'?

\begin{tabular}{ccccc}
\hline & Frequency & Percent & Valid Percent & Cumulative Percent \\
\hline Excellent & 14 & 28.0 & 28.0 & 28.0 \\
\hline Good & 21 & 42.0 & 42.0 & 70.0 \\
\hline Adequate & 5 & 10.0 & 10.0 & 80.0 \\
\hline Poor & 10 & 20.0 & 20.0 & 100.0 \\
\hline Total & 50 & 100.0 & 100.0 & \\
\hline
\end{tabular}

As shown in Table 9 that 42 percent of students have shown their responses for scale 2, for which the highest frequency is 21, which is good. The second highest frequency for this question is of scale 1, i.e. 14, which is excellent. This shows that the grammar rules are learned and used through activities by creating different situations when grammar rules are needed. These kinds of activities make the students become sharp and able to use the grammar rules accurately.

Research Item: Attractiveness of the text and physical makeup

In response to the question: 'Is the cover of the book appealing'?(Miekley, 2005). The result is as follows:

Table 10

'Is the cover of the book appealing'?

\begin{tabular}{ccccc}
\hline & Frequency & Percent & Valid Percent & Cumulative Percent \\
\hline Excellent & 10 & 20.0 & 20.0 & 20.0 \\
\hline
\end{tabular}




\begin{tabular}{ccccc}
\hline Good & 18 & 36.0 & 36.0 & 56.0 \\
\hline Adequate & 16 & 32.0 & 32.0 & 88.0 \\
\hline Poor & 3 & 6.0 & 6.0 & 94.0 \\
\hline Lacking & 3 & 6.0 & 6.0 & 100.0 \\
\hline Total & 50 & 100.0 & 100.0 & \\
\hline
\end{tabular}

As shown in Table 10 that 36 percent of students have shown their responses for scale 2, for which the highest frequency is 18 , which is good. The second highest frequency for this question is on scale 3, i.e. 16, which is adequate. This shows that some students have found the cover of the book less appealing and less attractive for them. It is not satisfactory for them. The evaluation of the textbook in this regard has helped in suggesting further improvement in the cover of the book. In response to the question: 'Is the visual imagery of high aesthetic quality? (Miekley, 2005). The result is as follows:

Table 11

'Is the cover of the book appealing'?

\begin{tabular}{ccccc}
\hline & Frequency & Percent & Valid Percent & Cumulative Percent \\
\hline Excellent & 16 & 32.0 & 32.0 & 32.0 \\
\hline Good & 21 & 42.0 & 42.0 & 74.0 \\
\hline Adequate & 9 & 18.0 & 18.0 & 92.0 \\
\hline Poor & 3 & 6.0 & 6.0 & 98.0 \\
\hline Lacking & 1 & 2.0 & 2.0 & 100.0 \\
\hline Total & 50 & 100.0 & 100.0 & \\
\hline
\end{tabular}

As shown in Table 11 that 42 percent of students have shown their responses for scale 2, for which the highest frequency is 21 , which is good. The second highest frequency for this question is on scale 1, i.e. 16, which is good. This shows that the visual aids referred for the textbook are of high aesthetic quality and it satiates the aesthetic sense of the students. It is occupied with such a pictorial quality that is appealing and attractive not only for the teachers but for the students as well. The visual imagery refers to the high quality adjectives and other forms of parts of speech used in a way that creates mental images in the minds of the students.

\section{Research Item: Context}

In response to the question: 'Does the text coincide with the course goals'?(Miekley, 2005). The result is as follows:

Table 12

Does the text coincide with the course goals'?

\begin{tabular}{ccccc}
\hline & Frequency & Percent & Valid Percent & Cumulative Percent \\
\hline Excellent & 17 & 34.0 & 34.0 & 34.0 \\
\hline Good & 18 & 36.0 & 36.0 & 70.0 \\
\hline Adequate & 8 & 16.0 & 16.0 & 86.0 \\
\hline
\end{tabular}




\begin{tabular}{ccccc}
\hline Poor & 4 & 8.0 & 8.0 & 94.0 \\
\hline Lacking & 3 & 6.0 & 6.0 & 100.0 \\
\hline Total & 50 & 100.0 & 100.0 & \\
\hline
\end{tabular}

As shown in Table 12 that 36 percent of students have shown their responses for scale 2, for which the highest frequency is 18, which is good. The second highest frequency for this question is of scale 1, i.e. 17, which is excellent. This shows that the text coincides with the course goals in a way that it achieves its objectives in a specific period. It is relevant to the ideas that are given in the goals and objectives. This idealizes the situation in the classroom that the students are learning what is relevant and required for them. In response to the question: 'Is the textbook appropriate for the students who will be using it? (Miekley, 2005). The result is as follows:

Table 13

'Is the textbook appropriate for the students who will be using it?

\begin{tabular}{ccccc}
\hline & Frequency & Percent & Valid Percent & Cumulative Percent \\
\hline Excellent & 18 & 36.0 & 36.0 & 36.0 \\
\hline Good & 15 & 30.0 & 30.0 & 66.0 \\
\hline Adequate & 8 & 16.0 & 16.0 & 82.0 \\
\hline Poor & 5 & 10.0 & 10.0 & 92.0 \\
\hline Lacking & 4 & 8.0 & 8.0 & 100.0 \\
\hline Total & 50 & 100.0 & 100.0 & \\
\hline
\end{tabular}

As shown in Table 13 that 36 percent of students have shown their responses for scale 1, for which the highest frequency is 18 , which is excellent. The second highest frequency for this question is on scale 2, i.e. 15, which is good. This shows that the textbook is appropriate for the students who will be using it. It reinforces the concepts and makes it better for the students to understand the main ideas textuality of the texts. In response to the question: 'Is the textbook appropriate for the teacher who will be teaching it'?(Miekley, 2005). The result is as follows:

Table 14

'Is the textbook appropriate for the teacher who will be teaching it'

\begin{tabular}{ccccc}
\hline & Frequency & Percent & Valid Percent & Cumulative Percent \\
\hline Excellent & 18 & 36.0 & 36.0 & 36.0 \\
\hline Good & 20 & 40.0 & 40.0 & 76.0 \\
\hline Adequate & 8 & 16.0 & 16.0 & 92.0 \\
\hline Poor & 2 & 4.0 & 4.0 & 96.0 \\
\hline Lacking & 2 & 4.0 & 4.0 & 100.0 \\
\hline Total & 50 & 100.0 & 100.0 &
\end{tabular}

As shown in Table 14 that 40 percent of students have shown their responses for scale 2, for which the highest frequency is 20, which is good. The second highest frequency for this question is of scale 1, i.e.18, which is excellent. This shows that the textbook is appropriate for the teachers who will be teaching it. It is full of such 
exercises that are useful for the teachers to imply in the classroom and enhance the communicative competence of the students. The mental work and practices of such types are responsible to create a bond between teachers and students.

Table 15

Descriptive Analysis

\begin{tabular}{|c|c|c|c|c|c|c|c|}
\hline & $\mathbf{N}$ & Min & Max & Mean & Std. & Kurtosis & Std. Error \\
\hline $\begin{array}{l}\text { 1. Is the subject matter presented } \\
\text { either topically or functionally in a } \\
\text { logical and organized manner? }\end{array}$ & 50 & 1 & 4 & 1.56 & .733 & 1.287 & .662 \\
\hline $\begin{array}{l}\text { 2. Are the reading selections } \\
\text { authentic pieces of language? }\end{array}$ & 50 & 1 & 4 & 2.00 & .833 & -.414 & .662 \\
\hline $\begin{array}{l}\text { 3. Are the grammar rules } \\
\text { presented in a logical manner and } \\
\text { in increasing order of difficulty? }\end{array}$ & 50 & 1 & 5 & 2.14 & 1.195 & .034 & .662 \\
\hline $\begin{array}{l}\text { 4. Are the new vocabulary words } \\
\text { presented in a variety of ways? }\end{array}$ & 50 & 1 & 5 & 1.92 & .966 & 1.264 & .662 \\
\hline $\begin{array}{l}\text { 5. Are the new vocabulary words } \\
\text { repeated in subsequent lessons to } \\
\text { reinforce their meaning and use? }\end{array}$ & 50 & 1 & 5 & 2.22 & .966 & -.059 & .662 \\
\hline $\begin{array}{l}\text { 6. Are there interactive and } \\
\text { task based activities that require } \\
\text { students to use new vocabulary to } \\
\text { communicate? }\end{array}$ & 50 & 1 & 5 & 2.50 & 1.282 & -.893 & .662 \\
\hline $\begin{array}{l}\text { 7. Do instructions in the textbooks } \\
\text { tell students to read for } \\
\text { comprehension? }\end{array}$ & 50 & 1 & 5 & 2.06 & 1.058 & -.171 & .662 \\
\hline $\begin{array}{l}\text { 8. Do the exercises promote } \\
\text { critical thinking of the text? }\end{array}$ & 50 & 1 & 5 & 2.18 & .850 & 1.570 & .662 \\
\hline $\begin{array}{l}\text { 9. Do the activities facilitate } \\
\text { student's use of grammar rules by } \\
\text { creating situations in which these } \\
\text { rules are needed? }\end{array}$ & 50 & 1 & 4 & 2.22 & 1.075 & -.887 & .662 \\
\hline $\begin{array}{l}\text { 10. Is the cover of the book } \\
\text { appealing? }\end{array}$ & 50 & 1 & 5 & 2.42 & 1.071 & .223 & .662 \\
\hline $\begin{array}{l}\text { 11. Is the visual imagery of high } \\
\text { aesthetic quality? }\end{array}$ & 50 & 1 & 5 & 2.04 & .968 & .679 & .662 \\
\hline $\begin{array}{l}\text { 12. Does the text coincide with the } \\
\text { course goals? }\end{array}$ & 50 & 1 & 5 & 2.16 & 1.167 & .238 & .662 \\
\hline $\begin{array}{l}\text { 13. Is the textbook appropriate for } \\
\text { the students who will be using it? }\end{array}$ & 50 & 1 & 5 & 2.24 & 1.271 & -.314 & .662 \\
\hline $\begin{array}{l}\text { 14. Is the textbook appropriate for } \\
\text { the teacher who will be teaching } \\
\text { it? }\end{array}$ & 50 & 1 & 5 & 2.00 & 1.030 & 1.313 & .662 \\
\hline Valid N (listwise) & 50 & & & & & & \\
\hline
\end{tabular}

\section{Conclusion}

The findings of the study are related to the practical concerns in relation to course objectives, subject matter, linguistic issues, and skills, variety of tasks and layout of materials. Teaching English to learners is not an easy task. This teaching material should be modified with regularity according to the needs of the learners. If 
needs are analyzed then it would become very easy for the practitioners to deal with each of the learners individually and enhance their language proficiency and communicative competence. To check the pedagogical value and suitability of the textbook material evaluation is done. According to the results the English taught to the students of BS Criminology at the University of Sargodha is accurate for the students and is fulfilling their communicative needs. The book has the key features which are proved to be motivational for the students. The kind of vocabulary, grammar and exercises are given in the book are no doubt designed very carefully and systematically. The illustrations and many activities related to the technique of skimming and scanning are very much responsible to improve the critical thinking of the students.

The layout of the materials is properly done with the help of flow charts, complete tables and tree diagrams which are considered to make the students aware of the salient ideas of the text. The elocution practices are done with the teachers in the classrooms that make the students more competent and proficient. It is difficult for the learners to think about the texts critically without going through different tasks. Similarly, results show that students are provided with such tasks to perform so they may understand things in a better way. The strategies to grasp the meanings of the unknown words from the context make the students even sharper. Hence, it is found from the results that not only the theoretical work but the practical work is equally important to make the learners of ESP perform in a better way. Furthermore, material evaluation is done to check the effectiveness of the textbook according to the capabilities of the learners. Hence, material evaluation paves a way to improve what lacks in the materials.

\section{Recommendations and Implications}

The following study is helpful in the aspect of material evaluation. The key feature of this research has highlighted the importance of material evaluation for the students of criminology. As the section of discussion shows that the ESP textbook for the students of Criminology is designed systematically and fulfills the needs of the learners. It is implied for further researches in ESP to evaluate the materials according to the needs of the learners. Various practical concerns in relevance to internal and external evaluation have been investigated in this research.

In addition to its implications, it recommends the modification and redesigning of the courses according to the needs and wants of the learners. The data represented in the preceding section points out the linguistic varieties and skills including the physical makeup of the book i.e. suitable for the students of BS Criminology. Similarly, material evaluation paves the way to maintain the demands of the learners. Hence, material evaluation construes the logicality and instructional guidelines for the practitioners and learners. 


\section{References}

ABBASIAN, G. R., \& Mahdavi, A. (2011). Four pairs of binoculars watching a single prey: Evaluation of Iranian ESP textbooks:(teachers vs. students). Journal of English studies 1, 51-66.

Al Fraidan, A. (2012). Evaluation of Two ESP Textbooks. English Language Teaching, 5(6), 43-47.

Danaye Tous, M., \& Haghighi, S. (2014). Evaluation of ESP textbooks: Evidence from ESP textbook of computer engineering major. International Journal of Research Studies in Language Learning, 3(2), 55-68.

El-Sakran, A. T. (2012). Evaluation of an English for Specific Purposes (ESP) book for students of Islamic and Arabic studies. English for Specific Purposes World, 34(12), 45-53.

Hutchinson, T., \& Waters, A. (1987). English for specific purposes. Cambridge university press.

Katsara, O. (2008). Aspects of motivation within the context of an ESP course. ESP World Journal, 7(3), 1-26.

Liton, H. A. (2015). ESP Learners' Needs Related Learning for the Workplace: A Pragmatic Study for Business School. International Journal of Instruction, 8(2), 3-16.

Kaur, S., \& Khan, A. M. (2010). Language needs analysis of art and design students: Considerations for ESP course design. ESP World, 9(2), 1-16. 